\title{
Uma análise de reflexões e de conhecimentos construídos e mobilizados por um grupo de professores no ensino de números decimais para o sexto ano do Ensino Fundamental
}

\section{Analysis of reflections and knowledge built and mobilized by a group of teachers to teach decimal numbers to the sixth year of Secondary School}

\author{
Adriana Fátima de Souza Miola* \\ Patrícia Sandalo Pereira**
}

\begin{abstract}
Resumo: Este artigo tem por finalidade apresentar um recorte da dissertação de mestrado, desenvolvida no Programa de Pós-Graduação em Educação Matemática da Universidade Federal de Mato Grosso do Sul - UFMS. Traz uma análise dos conhecimentos construídos e mobilizados por um grupo de professores durante a realização de seis encontros acerca do ensino de números decimais. Para análise dos dados foi utilizado o modelo teórico desenvolvido por Lee Shulman sobre a base de conhecimentos para o ensino, focando as três vertentes: o conhecimento específico, pedagógico e curricular do conteúdo. A formação do grupo possibilitou momentos de estudo, escolha, aplicação e reflexão. Os resultados revelam que as trocas de experiência e o planejamento elaborado coletivamente propiciaram, além da conscientização sobre a necessidade da base de conhecimentos, a importância de discutir e planejar em grupo. Apontaram ainda que os encontros contribuíram para que os sujeitos expusessem as suas dúvidas, refletindo sobre a sua prática.
\end{abstract}

Palavras-chave: Educação Matemática. Formação de professores. Ensino de decimais.

Abstract: This paper presents an analysis of the knowledge built and mobilized by a group of teachers throughout six meetings about decimal numbers teaching. The theoretical model developed by Lee Shulman about the knowledge basis for teaching was used for the data analysis, with focus on three aspects: the specific, pedagogical and curricular knowledge of content. The group work enabled moments of study, choices, application, and reflection. Results revealed that sharing experience and planning together made the group aware of the need of a knowledge basis, as well as the importance of discussing and planning as a group. They also pointed out that the

\footnotetext{
*Professora da Universidade Federal da Grande Dourados. E-mail: <drica220@yahoo.com.br>

** Professora da Universidade Federal de Mato Grosso do Sul. E-mail: <patriciasandalop@uol.com.br>
} 
meetings provided the participants with opportunities of sharing doubts and reflecting upon their practice.

Keywords: Mathematical Instruction. Teachers' Education. Teaching of decimals.

\section{Introdução}

Este artigo tem por finalidade apresentar a dissertação de mestrado que foi desenvolvida no Programa de Pós-Graduação em Educação Matemática da Universidade Federal de Mato Grosso do Sul - UFMS. O intuito desta pesquisa foi investigar os conhecimentos de um grupo de professores sobre os números decimais. Adotamos a teoria desenvolvida por Shulman (1986) como pressuposto teórico da pesquisa, por apontar os conhecimentos a serem investigados durante a realização dos encontros com os professores, além de alicerçar teoricamente o estudo em pauta.

Desenvolvemos esta pesquisa juntamente com um grupo de professores por acreditarmos que o trabalho realizado em grupo traz reflexões que podem contribuir para o desenvolvimento profissional dos envolvidos. O trabalho foi realizado coletivamente e possibilitou momentos de discussões a respeito do conceito e das operações básicas com números decimais, mostrando as principais dificuldades conceituais e operacionais envolvendo o conteúdo. Dessa forma, deu-se a construção e a reconstrução do conhecimento por parte dos professores, concedendo-se sentido à reflexão sobre a própria prática, conforme ideias difundidas por autores, tais como Bolzan (2002) e Piatti (2006).

A escolha deste conteúdo deve-se ao fato de que o trabalho escolar com este tópico começa, em geral, nos anos iniciais do Ensino Fundamental $\left(4^{\circ}\right.$ e $5^{\circ}$ anos) e é retomado nos dois anos subsequentes ( $6^{\circ}$ e $7^{\circ}$ anos) de forma mais sistemática, sendo revisto em diferentes momentos nas demais séries do Ensino Fundamental e do Ensino Médio. Nesse sentido, os Parâmetros Curriculares Nacionais - PCN (BRASIL, 1998) orientam

Embora as representações fracionárias e decimais dos números racionais sejam conteúdos desenvolvidos nos ciclos iniciais, o que se constata é que os alunos chegam ao terceiro ciclo sem compreender os diferentes significados associados a esse tipo de número e tampouco os procedimentos de cálculo, em especial os que envolvem os racionais na forma decimal (BRASIL, 1998, p. 100).

Acreditamos que parte das dificuldades dos alunos está na construção do conceito da representação decimal do número racional, porque, geralmente, eles não percebem que a fração possui também o estatuto de número. De acordo com Bittar e Freitas (2005), os números decimais já fazem parte do contexto 
diário dos alunos mesmo antes de frequentarem a escola. Desse modo, mesmo sem conhecer formalmente os "números com vírgula", eles já tiveram contato com a escrita decimal, sobretudo, no contexto monetário, através de folhetos de supermercado, propagandas etc. Esse conhecimento, se explorado pelo professor, pode contribuir para a construção do conceito de números decimais. Conforme proposto nos PCN (BRASIL, 1998, p. 101):

No terceiro e no quarto ciclos a abordagem dos racionais, em continuidade ao que foi proposto para os ciclos anteriores, tem como objetivo levar os alunos a perceber que os números naturais são insuficientes para resolver determinadas situações-problema como as que envolvem a medida de uma grandeza e o resultado de uma divisão.

Entretanto, Moreira e David (2007) relatam os fortes questionamentos sobre a abordagem que se desenvolve na licenciatura em relação à preparação do futuro professor para o trabalho pedagógico escolar no que se refere à construção dos racionais.

Este estudo justifica-se, também, pela escassez de pesquisas com professores e que abordem o mencionado conteúdo nos anos finais do Ensino Fundamental.

Com base nas justificativas apresentadas anteriormente e com a clareza de que um dos momentos cruciais no desenvolvimento de uma pesquisa é o estabelecimento de uma pergunta, visto que, como afirmam Araújo e Borba (2004, p. 39), "ao realizar uma pesquisa torna-se importante que, após a definição do tema, seja encontrado um foco, que se traduz, de forma especifica, em um problema ou pergunta de pesquisa", estabeleceu-se a seguinte questão norteadora: a partir da constituição de um grupo de professores e pesquisadores, quais conhecimentos e práticas docentes são colocados em ação, visando o ensino de números decimais nos sextos anos do Ensino Fundamental? Explicitando melhor, queremos investigar o quanto um trabalho produzido coletivamente pode contribuir para possíveis alterações no contexto da sala de aula.

A partir daí, temos como objetivo geral de pesquisa: analisar as reflexões sobre as práticas docentes e os conhecimentos construídos e mobilizados por um grupo de professores durante a realização de encontros visando o ensino de números decimais no sexto ano do Ensino Fundamental.

A coleta de dados foi feita nos encontros realizados no Laboratório de Ensino de Matemática (LEMA) da Universidade Federal de Mato Grosso do Sul - UFMS. Os professores que participaram da pesquisa estiveram vinculados ao Projeto de Extensão intitulado "Laboratório de Ensino de Matemática (LEMA) na Formação e na Prática do Professor". Ademais, para atingir o objetivo geral, elencamos três objetivos específicos: 
- Identificar, durante a realização dos encontros, os conhecimentos específicos, pedagógicos e curriculares dos professores sobre o ensino de números decimais.

- Analisar as inferências na elaboração do planejamento feito pelo grupo sobre a prática pedagógica dos professores no ensino de decimais.

- Analisar as inferências no desenvolvimento do planejamento elaborado pelo grupo sobre a prática pedagógica dos professores no ensino de decimais, após a aplicação em sala de aula.

\section{A representação decimal e o número decimal}

Os números decimais acompanharam os inúmeros passos dados pela humanidade em busca da construção do conceito de número, para que se chegasse, hoje, aos números que comumente chamamos de decimais.

O surgimento do sistema de numeração decimal permitiu uma notação simples e coerente de todos os números, possibilitando a realização de inúmeros cálculos, até então inconcebíveis, modificando profundamente a existência do ser humano, abrindo caminhos para o desenvolvimento da matemática, das ciências e das técnicas. (IFRAH, 1997).

O tratado de Aritmética de Al-Kawarizmi (780-850) é considerado a primeira obra a tratar detalhadamente as operações de cálculo, permitindo o uso do número decimal como instrumento matemático. Essa obra, que tinha como principal objetivo ser eminentemente pedagógica, também trata das frações, dando nomes particulares para aquelas que têm como numerador uma unidade, por exemplo, $\frac{1}{10}$.

O primeiro matemático que utilizou os decimais foi o árabe Al-Uglidisi, no século X. Sua obra trata de maneira natural as frações decimais, mostrando as vantagens do sistema decimal nas operações. Outra obra importante foi o livro $A$ chave da aritmética escrito, em 1429, pelo astrônomo e matemático AL-kasi. O autor foi o primeiro a explicar uma teoria das frações decimais e a noção dos números decimais. Ele dedica grande atenção às conversões de frações sexagesimais em frações decimais e vice-versa, assim como reconhece o número decimal como uma grande descoberta (PÉREZ, 1997).

Somente no século XVI, os matemáticos perceberam que seria possível utilizar a mesma escrita dos números inteiros para o não inteiro. Boyer (1996) confirma a contribuição do uso das frações decimais, descoberta em manuscritos medievais, como um elemento importante, que se usava desde a China Antiga, na Arábia Medieval e na Europa do Renascimento. Segundo o autor, assim como 
a metrologia sexagesimal levou à numeração sexagesimal na Mesopotâmia, a adesão à ideia decimal de pesos e medidas fez a China ter um hábito decimal no tratamento de frações.

Em 1579, François Viète recomendou constantemente o uso das frações decimais ao invés das sexagesimais e, em 1585, outra recomendação a favor da escala decimal, tanto para frações, quanto para inteiros, foi feita pelo mais importante matemático dos Países Baixos, Simon Stevin de Bruges. Cabe ressaltar que Stevin não foi o inventor das frações decimais, tampouco o primeiro a sistematizá-la. Os povos da China antiga assim como os da Arábia Medieval e da Europa do Renascimento já as utilizavam.

Quando Viéte indicou-as, em 1579, elas já eram aceitas pelos matemáticos pesquisadores, contudo, somente seria admitida entre a sociedade quando Stevin explicou o sistema de maneira elementar e completo, em que ensinava como efetuar, de forma muito simples, todas as computações necessárias entre os homens apenas com os números inteiros.

Stevin escrevia num círculo acima ou depois de cada dígito a potência de dez, assumida como divisor (BOYER, 1996). Apesar de Stevin pensar corretamente em relação às frações decimais, a sua notação seguia a de Bombelli, que era mais apropriada à álgebra. No entanto, a notação moderna das frações decimais apareceu logo depois na tradução em inglês de Napier, em 1617, em que a parte inteira era separada por um ponto da parte fracionária. Com a obra de Napier de 1619, o ponto tornou-se padrão na Inglaterra, entretanto, muitos países da Europa usam a vírgula.

Ifrah (1997) assevera que o uso do ponto separando a parte inteira da fracionária só se estabeleceu a partir das obras de Simon Stevin, responsável pela extensão dos números decimais no Ocidente, e de JostBürgi e Magini. Quanto à vírgula, foi Wilbord Snellius que a inventou, no início do século XVII.

Pérez (1997), em seus estudos, salienta que o redescobrimento dos números decimais aparece associado a uma época de grandes transformações sociais, como o descobrimento da ciência moderna de Copérnico (1543) e dos estudos de Newton (1687), como também transformações religiosas, filosóficas e econômicas. Os cálculos de distâncias, as repartições de terras e o crescimento do comércio incentivaram o desenvolvimento dos números decimais.

As frações decimais, ou números decimais, foram incorporados ao nosso sistema de numeração muitos séculos depois de sua invenção. Muitos erros tiveram que ser superados ao longo desses séculos para que, hoje, pudéssemos interpretar um número como é o caso de 5,5. Pérez (1997) registra que, por volta de 1793, a França estabeleceu, pela primeira vez, o sistema métrico decimal, tendo como objetivo principal os interesses políticos, definindo unidades de medidas 
regionais e local válidas para todo território nacional, evitando divisões complicadas em cálculos comerciais e fraudes que resultavam em erros no comércio.

A adaptação do sistema métrico decimal favoreceu a extensão do cálculo com decimais. Mas os números decimais ganharam caráter de números somente no final do século XIX, quando Cantor e outros matemáticos iniciaram estudos sobre os fundamentos da Matemática.

Segundo Penteado (2004), Cantor empregou um argumento baseado no princípio posicional do sistema decimal para provar que o conjunto dos números reais era enumerável. Cantor demonstrou, com rigor matemático, que é possível estabelecer uma comparação entre conjuntos infinitos, ou seja, mostrar que nem todos os conjuntos infinitos são de mesmo tamanho.

Penteado (2004) aponta que uma das maiores dificuldades encontradas por Cantor foi em relação aos números irracionais, os quais, ele propôs, já em 1872, representar por sucessão infinita de racionais. Assim o número $\sqrt{2}$ era representado por uma sucessão infinita de racionais: $1 ; 1,4 ; 1,41$. Porém, observou-se que os pontos irracionais, como, $\sqrt{2}$ caiam entre pontos racionais, indicando que o conjunto não era contínuo. Com isso, Cantor fez um aprofundamento teórico nos dados deixados por Dedekind, Bolzano, entre outros, que também estudavam as propriedades do contínuo, e mostrou que os números racionais podiam ser colocados em correspondência biunívoca com os números inteiros. Demonstrou, além disso, que não havia correspondência biunívoca entre o conjunto dos inteiros positivos e conjunto de pontos de uma reta e, consequentemente, entre o primeiro conjunto e os números reais.

Buscamos, na história, fatos que pudessem esclarecer o uso da representação decimal utilizada atualmente e percebemos que a construção e a apropriação dos números decimais possuem certa semelhança nos processos de ensino e aprendizagem em nossas escolas. $\mathrm{Na}$ atualidade, os alunos ou até mesmo professores definem os números decimais como sendo números "quebrados", ou "com vírgula", confundindo a natureza dos números racionais com sua representação escrita.

Conforme afirma Padovan (2000, p. 41): "é como se a sua multiplicidade de significados pudesse se resumir a uma vírgula". Com isso, muitos alunos chegam ao sexto ano com o conhecimento sobre números decimais resumidos a sua representação, sem compreender o seu real significado.

Os números decimais são equivalentes às frações decimais, as quais lhe deram origem, são representados por vírgula e por ponto na calculadora e, em alguns países (países anglo-saxão), os algarismos à esquerda da vírgula indicam as quantidades inteiras, enquanto que os algarismos à direita representam partes 
do inteiro (décimos, centésimos, milésimos e assim por diante). As frações e os decimais podem, em alguns casos, representar, de maneiras diferentes, as mesmas coisas.

Os números decimais pertencem ao conjunto dos números racionais, podendo ser representados por frações decimais e/ou pela representação decimal finita. Segundo Niven (1984), o número racional $\frac{1}{2}$ possui outra representação diferente das formas $\frac{2}{4}, \frac{3}{6}, \frac{4}{8}$ etc. A saber, a representação decimal 0,5 , sendo esta representação decimal, finita. Já outros números possuem a sua representação decimal infinita, ou seja, que não termina, como $\frac{1}{6}=0,166 \ldots, \frac{5}{11}=0,454545 \ldots$ Mas quais números racionais têm uma representação decimal finita? Para Niven (1984), qualquer fração decimal finita pode ser escrita como uma fração ordinária, com denominador igual a uma potência de dez.

Um exemplo trazido pelo autor é a fração $\frac{8625}{10000}$, da qual, ao torná-la irredutível, obtemos, dividindo 10000 por 125, que é o maior divisor entre 10000 e 8625 , a fração $\frac{69}{80}$. Segundo ele, tanto o inteiro 80 quanto 10000 têm somente dois fatores primos, 2 e 5 . Com isso, ele concluiu: "Um número racional, na forma irredutível $\frac{a}{b}$, tem uma representação decimal finita, se, e somente se, $b$ não tiver outros fatores primos além de 2 e 5.” (NIVEN, 1984, p. 36).

Penteado (2004) destaca que o número que possui uma representação decimal finita é racional, sendo a sua representação fracionária: $\frac{\mathrm{a}_{\mathrm{q}} \mathrm{a}_{1} \mathrm{a}_{2} \ldots \mathrm{a}_{\mathrm{n}}}{10^{\mathrm{n}}}$ e se tivermos um número racional, no seu registro fracionário, com seu denominador contendo, apenas, os fatores 2 e 5 , este número admite uma representação decimal finita. De fato, pois $\frac{p}{q}=\frac{p}{2^{m} \cdot 5^{n}}$, se $\mathrm{m} \geq \mathrm{n}$, basta multiplicar a fração por $5^{\mathrm{m}-\mathrm{n}}$, obtendo-se, $\frac{p \cdot 5^{m-n}}{2^{m} \cdot 5^{n}}=\frac{p \cdot 5^{m-n}}{2^{m} \cdot 5^{n}}=\frac{C}{10^{m}}$. Portanto $\frac{p}{q}$ admite uma representação com " $\mathrm{m}$ " casas decimais. Mas se $\mathrm{n} \leq \mathrm{m}$, basta multiplicar a fração por $2^{\mathrm{m}-\mathrm{n}}$, obtendo-se $\frac{p \cdot 2^{m-n}}{10^{n}}=\frac{d}{10^{m}}$. Portanto $\frac{p}{q}$ admite uma representação com "n" casas decimais.

De acordo com Pérez (1997), um número decimal é um número que possui, ao menos, uma escrita em forma de fração decimal, sendo que a fração decimal é uma fração cujo denominador é uma potência de 10. Assim, um número $n$ é decimal se possuir a forma $\mathrm{n}=\frac{A}{10^{a}}$, sendo $A$ e $a$ números inteiros. Com isso, um número inteiro positivo ou negativo é também número decimal, pois podemos escrevê-los como uma fração com denominador sendo uma potência de dez, como o número inteiro $6=\frac{6}{10^{\circ}}$. 
Considerando toda a escritura decimal de todos os números reais, teremos as escritas decimais, sendo que as escritas finitas representam os números decimais; por sua vez, as escritas infinitas periódicas representam os números racionais, enquanto as infinitas não periódicas representam os números irracionais. (PÉREZ, 1997).

Ressaltamos que tomaremos, neste trabalho, como definição de números decimais, o conjunto formado por todos os números que podem ser escritos como uma fração cujos termos são números inteiros e onde o denominador é uma potência de 10 .

No Quadro 1, sintetizamos a definição de número decimal, a partir do seguinte organograma:

Quadro 1 - Representação do conjunto dos números racionais

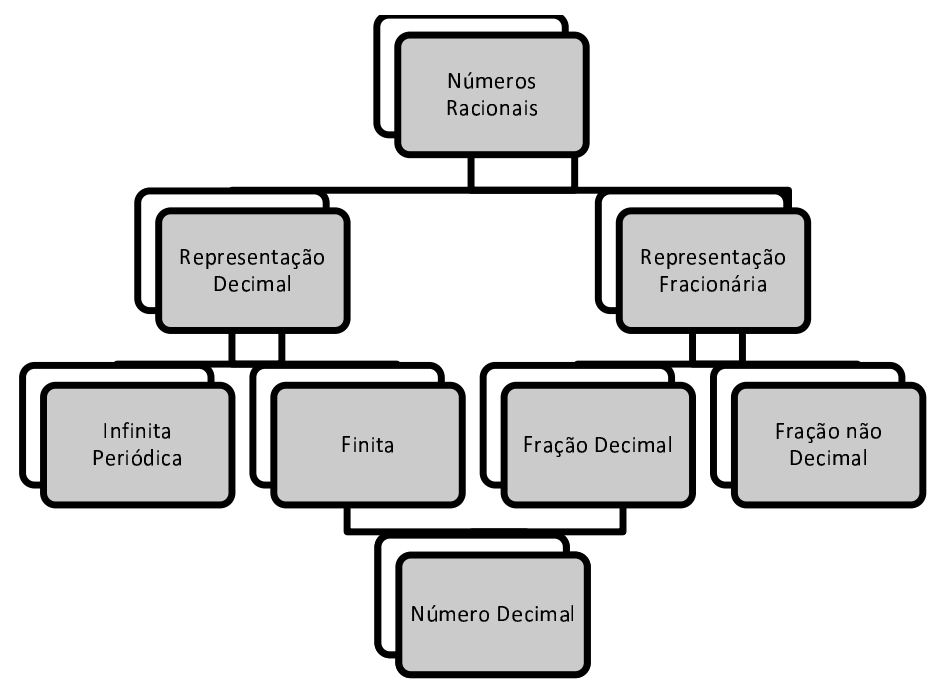

Fonte: As autoras.

Segundo Bittar e Freitas (2005), apesar da diferente representação escrita, é fundamental a compreensão de que todo número decimal pode ser representado por uma fração e todo número fracionário pode ser representado sob a forma decimal.

Compartilhamos a ideia defendida pelos autores Pérez (1997) e Bittar e Freitas (2005), que também é recomendada nos Parâmetros Curriculares Nacionais - PCN (BRASIL, 1998), de que alguns recursos, como é o caso do material dourado, podem auxiliar o trabalho dos professores no ensino das relações entre as diferentes representações do número racional. 
Bittar e Freitas (2005) valorizam o uso do material dourado, considerando-o como um material adequado ao trabalho com os números decimais, pois o uso dele também pode ser feito para estabelecer relações entre os números decimais e as frações decimais.

Cabe lembrar que quando propusemos ao grupo, que formamos para este estudo, a discussão sobre o ensino de números decimais, tínhamos o intuito de contribuir para a compreensão do conceito de números racionais, tendo em vista que, como defendido por Bittar e Freitas (2005), mais do que aplicar uma regra (por exemplo: 10 no denominador coloca-se um algarismo após a vírgula, 100 no denominador, colocam-se dois algarismos após a vírgula), "é importante que os alunos manipulem esses números, descobrindo suas propriedades sem, entretanto, serem obrigados a decorá-las, o que representaria uma regra com pouco sentido para eles". (BITTAR; FREITAS, 2005, p. 177).

Também concordamos com as ponderações de Nacarato (2000, p. 105) quando ressalta que, "se a humanidade levou tantos séculos para abstrair um conceito e criar formas de representação, por que não se levar isso em consideração, e não propiciar situações mais significativas para a criança?".

A partir desse ponto de vista, consideramos relevante tanto que o professor tenha conhecimento sobre a evolução histórica do conceito dos números decimais, quanto a existência de pesquisas sobre o campo dos racionais, especificamente dos números decimais.

\section{Conhecimentos necessários ao ensino: contribuições de Shulman}

Em meados da década de 80, Shulman (1986) elaborou um mapeamento dos programas de pesquisa sobre ensino, tornando-se um dos pioneiros nos estudos sobre os conhecimentos do professor. A partir de suas investigações acerca das pesquisas sobre ensino, dos programas de formação docente e dos programas de avaliação e certificação de professores, Shulman (1986) demonstrou que, até os anos 70, a preocupação em relação à formação de professores era sobre o conhecimento do conteúdo, de tal sorte que as teorias e os métodos ficavam em segundo plano.

Já nos anos 80 , a ênfase maior passou a ser dada às questões procedimentais, e o conteúdo assumiu papel secundário. Partindo das críticas feitas às antigas abordagens, Shulman (1986) defende a recuperação das pesquisas sobre o ensino dos conteúdos e consolida a corrente - base de conbecimento - que se tornou uma referência para as reformas no ensino americano nos anos 90 . Nesse sentido, algumas questões são levantadas acerca da compreensão sobre os conhecimentos dos professores. 
[...] Que conhecimento-base? Há conhecimento suficiente sobre ensino para apoiar um conhecimento-base? Não seria o ensino um pouco mais que um estilo pessoal, comunicação, conhecimento de uma matéria, e aplicação de resultados de pesquisas recentes sobre a eficácia do ensino? (WILSON; SHULMAN; RICHERT, 1987a, p. 4).

Nos estudos realizados em 1986, Shulman critica a dicotomia existente entre conhecimento do conteúdo específico e conhecimento pedagógico que é encontrada entre os professores nos Estados Unidos, apontando a necessidade de outro eixo - conhecimento do conteúdo no ensino - vinculando aos dois já existentes.

Propõe, assim, que os professores precisam ter diferentes tipos de conhecimentos, entre eles, o conhecimento do conteúdo específico, o conhecimento pedagógico do conteúdo e o conhecimento curricular. Embora, no artigo em comento, o autor tenha se limitado a discutir apenas três eixos da base de conhecimento por ele proposto, enfatiza que esta base de conhecimento inclui inúmeras categorias. Mizukami (2004, p. 5) assevera:

A base de conhecimento para o ensino consiste de um corpo de compreensões, conhecimentos, habilidades e disposições que são necessários para que o professor possa propiciar processos de ensinar e de aprender, em diferentes áreas de conhecimento, níveis, contextos e modalidades de ensino. Esta base envolve conhecimentos de diferentes naturezas, todos necessários e indispensáveis para atuação profissional. É mais limitada em cursos de formação inicial, e se torna mais aprofundada, diversificada e flexível a partir da experiência profissional refletida e objetivada. Não é fixa e imutável. Implica construção contínua, já que muito ainda está para ser descoberto, inventado, criado.

Nas ponderações de Shulman (1987), percebemos que os três aspectos organizam-se em categorias, sendo elas: conhecimento do conteúdo, conhecimento pedagógico geral, conhecimento do currículo, conhecimento do conteúdo pedagógico, conhecimento dos alunos, conhecimento de contextos educacionais e conhecimentos sobre os fins educacionais, propósitos e valores. "Estes saberes se consolidam em um amálgama pedagógico que une conteúdo e pedagogia" (BORGES, 2001, p. 10).

Lembramos que essa base é apresentada ao longo de quatorze anos pelo autor. Este fato parece deixar, pois, evidente a validade de suas pesquisas.

Dentre as categorias que compõem a Base de Conhecimentos para o Ensino, utilizaremos, em nosso estudo: conhecimento específico do conteúdo ${ }^{1}$, conbecimento

\footnotetext{
${ }^{1}$ Utilizaremos a expressão conhecimento do conteúdo específico como tradução da expressão subject matter content Knowledge, com base nos estudos de Mizukami et al. (2002).
} 
pedagógico do conteúdo e conhecimento curricular do conteúdo. A seguir, enfocamos com mais detalhes cada um desses aspectos.

O conhecimento específico do conteúdo refere-se ao entendimento do professor em relação à sua disciplina, incluindo informação factual, a organização de princípios e a identificação, a definição e a discussão de conceitos. Nesse sentido, Shulman (1986, p. 11) afirma:

Professores não devem ser somente capazes de definir para os alunos as verdades aceitas no âmbito da disciplina. Eles devem também explicar porque uma particular afirmação é dita garantida, e porque vale a pena saber e como isso se relaciona com outras afirmações. Tanto dentro da disciplina e fora dela, tanto na teoria como na prática. Além disso, nós esperamos que professores entendam porque um dado tópico é particularmente central para uma disciplina, ao mesmo tempo em que um outro pode ser de alguma forma periférico.

Shulman; Wilson e Richert (1987) asseveram que, além do entendimento dos fatos e dos conceitos de uma determinada matéria, é importante a compreensão de suas estruturas substantivas e sintáticas. Para considerar tais estruturas, os autores baseiam-se no modelo proposto por Schwab (1964).

A estrutura substancial diz respeito aos paradigmas ou quadros teóricos, dando sentido às estruturas de uma determinada ciência, o que exige um domínio em relação à organização conceitual dentro da disciplina. Incluem as ideias, os fatos e as concepções sobre o campo, assim como as relações entre essas ideias, fatos e concepções, ou seja, "são os vários modos que os conceitos e princípios básicos da disciplina estão organizados para incorporar seus fatos" (SHULMAN, 1986, p. 11).

As estruturas sintáticas, por sua vez, são o conjunto de formas em que a verdade, a falsidade, a validade e a invalidade são estabelecidas. "É o conjunto de regras para determinar o que é legitimo para ser dito no âmbito disciplinar e para determinar o que 'quebra' as regras" (SHULMAN, 1986, p. 11). Este tipo de conhecimento permite responder questões como:

Quais são as ideias e habilidades importantes neste domínio?

Como novas idéias são adicionadas e aquelas deficientes descartadas por aqueles que produzem conhecimento nesta área?

Ou seja, quais são as regras e procedimentos de um estudo sério ou investigação? (SHULMAN, 2001, p. 8).

\footnotetext{
2 Adotaremos a expressão conhecimento pedagógico do conteúdo como tradução da expressão pedagogical content knowledge, com base nos estudos de Mizukami et al. (2002), que discutem as pesquisas de Shulman.
} 
Para Mizukami (2004, p. 5), esta estrutura "envolve conhecimento de formas pelas quais a disciplina constrói e avalia novo conhecimento. É importante que o professor não só aprenda os conceitos, mas que os compreenda à luz do método investigativo e dos cânones de ciência assumidos pela área de conhecimento".

Acreditamos que este tipo de conhecimento não se refere apenas a entender o conteúdo em si, mas compreender, organizar e entender os processos de produção desse conteúdo, como também as diferentes perspectivas de relação entre tópicos de áreas distintas.

Tal amplitude de entendimento relacionada a esse conhecimento parece ser desnecessária a um professor de matemática, visto que muitos professores creem que o simples domínio do conteúdo é suficiente. Entretanto, a ampla compreensão de uma dada disciplina possibilita ao professor falar com mais propriedade sobre os seus conteúdos.

Diante disso, percebe-se que o conhecimento de um conteúdo exige do professor algo além do que simplesmente saber resolver problemas ou definir conceitos. Com base nisso, analisaremos, em nossa investigação, os conhecimentos explicitados por um grupo de professores em relação ao conteúdo de números decimais. Assim, verificaremos a compreensão que os sujeitos possuem deste conteúdo no que tange ao conceito de números decimais, a comparação de números decimais, bem como as principais operações e as relações entre os números decimais e o sistema de numeração decimal.

Para Shulman (1987) e seus colaboradores, o conhecimento específico do conteúdo ocupa um lugar central na base de conhecimento para o ensino. Afirmam, neste caso, que a compreensão pessoal do conteúdo pelo professor não é condição suficiente para que o profissional em questão seja capaz de ensinar, de tal modo que os professores devem encontrar diferentes maneiras de ensinar os seus conhecimentos aos alunos, utilizando representações, ilustrações, exemplos que facilitem a compreensão do conteúdo.

Outra categoria da base de conhecimento para o ensino a ser destacada é o conhecimento pedagógico do conteúdo. Nesta categoria, acham-se incluídas as diferentes formas de representações e analogias que o professor dispõe para facilitar a aprendizagem do aluno.

[...] Dentro da categoria do conhecimento pedagógico do objeto estudado, eu incluo, na maioria dos tópicos ensinados, regularmente na área de um professor, as formas mais úteis de representações dessas idéias, as analogias, ilustrações, exemplos, explicações e demonstrações mais poderosas - resumindo, as maneiras de representar e formular a matéria para torná-la compreensível para outros $[. .$.$] inclui uma compreensão do que faz o aprendizado de tópicos$ 
específicos tornarem-se fácil ou difícil: as concepções e pré-concepções que os alunos de idades e formação diferentes trazem para o ensino (SHULMAN, 1986, p. 12).

Assim, além do conhecimento específico do conteúdo, Shulman assegura que o professor necessita do conhecimento pedagógico do conteúdo. Para Mizukami (2004, p. 6), trata-se de

[...] um novo tipo de conhecimento, que é construído constantemente pelo professor ao ensinar a matéria e que é enriquecido e melhorado quando se amalgamam os outros tipos de conhecimentos explicitados na base. É uma forma de conhecimento do conteúdo. Inclui compreensão do que significa ensinar um tópico de uma disciplina específica assim como os princípios e técnicas que são necessários para tal ensino.

Entendemos que este conhecimento vai além dos conhecimentos do conteúdo em si para a essência do conhecimento a ser ensinado. Neste aspecto, estão inseridas, pois, as percepções e as concepções que os professores têm sobre as dificuldades de aprendizagem dos alunos, bem como o seu entendimento de um determinado assunto, além dos erros que são por eles cometidos. Com isso, o professor precisa conhecer diversas formas de representação que deem conta do conteúdo que ele pretende ensinar a seus alunos. Essa variedade de representações é adquirida tanto por pesquisas, quanto pela prática quotidiana do docente.

Por fim, destacamos o conbecimento curricular que, por sua vez, envolve o conhecimento dos professores sobre os materiais que podem ser utilizados para o ensino de uma disciplina específica (no nosso caso, materiais didáticos manipuláveis). Shulman (1986) mostra a necessidade da atualização profissional ao comparar o conhecimento curricular do professor e o conhecimento médico sobre os fármacos:

[...] O currículo e seus materiais associados são a matéria médica da pedagogia, a farmacopéia dos quais professores retiram ferramentas de ensino que apresentam ou exemplificam um conteúdo particular e remediam ou avaliam a adequação das realizações do estudante. Nós esperamos que um médico experiente entenda todos os diferentes tratamentos disponíveis para melhorar certa desordem, assim como as alternativas para circunstâncias particulares de sensibilidade, custo, interação com outras intervenções, conveniência, segurança ou conforto. Similarmente, nós temos que esperar que o professor experiente tenha tais entendimentos sobre alternativas curriculares para instrução [...] (SHULMAN, 1986, p. 13).

Este tipo de conhecimento compreende duas facetas: horizontal e vertical. O conhecimento curricular horizontal concerne à capacidade de relacionar conteúdos de outras disciplinas (interdisciplinaridade) com assuntos 
desenvolvidos numa determinada aula. Já o conhecimento curricular vertical é a relação de conteúdo trabalhado numa mesma disciplina, ou seja, a familiarização de tópicos que já foram ministrados com os que ainda serão ensinados, envolvendo os materiais que fazem parte deles. Ressaltamos que, neste trabalho, discutiremos somente a última faceta.

Neste momento, cabe ressaltar que, conforme defendido por Wilson; Shulman e Richert (1987), na maioria das vezes, esses conhecimentos (conteúdo específico, conhecimento pedagógico e curricular do conteúdo) estão totalmente ligados. Considerando que a prática docente exige um amplo conhecimento do professor sobre sua disciplina, podemos pontuar que a deficiência em relação a esses conhecimentos (específico e pedagógico e curricular do conteúdo) pode influenciar na capacidade de escolher um material didático que auxilie no desenvolvimento de uma aula. De fato:

[...] Ensinar conteúdos dos quais não se tem domínio é difícil e os professores usam uma variedade de táticas para lidar com essa tarefa. Alguns professores evitam ensinar o que não conhecem muito bem [...] ao ensinar o que eles não estão seguros, os professores optam por palestrarem sobre $\mathrm{o}$ assunto a solicitar que os alunos indaguem o que poderia levar o professor a um território desconhecido [...] Assim o conhecimento, ou a falta dele, no que diz respeito ao conteúdo, pode afetar nas críticas que os professores fazem ao material didático, como eles selecionam esse material para ensinar, como eles estruturam seus cursos, e como eles conduzem o processo de instrução [...]. (GROSSMAN; WILSON; SHULMAN, 1989, p. 9).

Ao tentarmos olhar para os conhecimentos dos professores a partir de uma dessas categorias, observaremos que nenhuma existe por si só, que um conhecimento mobilizado por um professor pode depender de duas ou até das três categorias. Este fato foi comprovado por algumas pesquisas realizadas com professores que apontam o entrelaçamento desses conhecimentos (ESTEVES, 2009; OLIVEIRA, 2010; SILVA, 2010).

Essa relação imbricada pode ser identificada na prática dos professores, sujeitos desta investigação, ao propomos a produção de um material didático manipulável para auxiliar no planejamento de uma sequência de atividades sobre o ensino de números decimais que serão desenvolvidas em sala de aula.

Diante disso, concordamos com Shulman (1987, p. 22) ao considerar que "uma compreensão apropriada do conhecimento - base na educação, às fontes para este conhecimento, e as complexidades dos processos pedagógicos tornarão mais provável o surgimento de profissionais com excelência pedagógica". Nesse sentido, Ponte (2000) declara ser necessário investigar em que consiste o conhecimento do professor e em quais processos ele aprende e desenvolve-se profissionalmente. 


\section{Os encontros e os procedimentos}

Foram realizados seis encontros, envolvendo um grupo de professores, aos quais atribuímos nomes fictícios - Veriani, Solange, Cristiane, João, Junior e Alexandre - os quais atuam nos sextos anos do Ensino Fundamental da rede pública do município de Campo Grande - MS durante o ano de 2010 e 2011.

Os encontros foram realizados no Laboratório de Ensino de Matemática (LEMA) da Universidade Federal de Mato Grosso do Sul - UFMS. O objetivo dos encontros foi de conhecer os professores (crenças, concepções, etc.) acerca do ensino de números decimais, de criar um ambiente de discussão, de troca de experiências e de respeito e interesse, a partir de suas experiências e conhecimentos. Sendo assim, esforçamo-nos por garantir a transparência de nossos objetivos, porque não nos propusemos a ensinar a melhor maneira de trabalhar a representação decimal com os alunos de sextos anos, mas, como assinalamos anteriormente, conduzir os professores a questionar e refletir os seus conhecimentos e as suas práticas. A partir daí, elaborar conjuntamente um planejamento para ser trabalhado com seus alunos e, se necessário, reelaborá-lo.

Este trabalho é de cunho qualitativo. Os dados foram obtidos através do contato direto com os sujeitos pesquisados. A ênfase foi dada mais ao processo do que ao produto, permitindo um diálogo entre investigadores e os sujeitos, conforme orienta Bogdan e Biklen (1994). Assim, optamos por adotar, dentro dessa abordagem qualitativa, a Análise de Conteúdo, segundo proposta de Franco (2008) e Bardin (2008).

Para Bardin (2008, p. 40, grifo da autora)

A análise de conteúdo aparece como um conjunto de técnicas de análise das comunicações que utiliza procedimentos sistemáticos e objetivos de descrição do conteúdo das mensagens [...] A intenção da análise de conteúdo é a inferência de conhecimentos relativos ás condições de produção (ou, eventualmente, de recepção), referencia essa que recorre a indicadores (quantitativos ou não).

Os momentos de fala retirados das transcrições dos encontros foram identificados por E1, E2, E3, E4, E5 e E6, correspondendo a cada encontro, e aparecerão entre parênteses. Todos os encontros foram transcritos e analisados, sendo sua análise apresentada no tópico a seguir.

\section{Análise dos dados}

A partir do referencial teórico baseado em Shulman $(1986,1987)$ e do material obtido durante os seis encontros realizados, os dados foram analisados considerando-se os conhecimentos conceituais, as operações envolvendo 
números decimais, as relações entre a representação fracionária e decimal e o material manipulável elaborado pelo grupo para o ensino de números decimais.

Em relação ao conhecimento conceitual, essa categoria abarca os conhecimentos específicos de números decimais, como a definição, a comparação, a escrita e a leitura desse conteúdo. Em outras palavras:

O conhecimento do conteúdo da disciplina deve envolver o conhecimento para ensinar, não como um conjunto de regras relativas à aplicação do conteúdo, mas os conhecimentos relativos à natureza e aos significados dos conteúdos, o desenvolvimento histórico, os diversos modos de organizá-los (CURI, 2004, p. 4).

Analisaremos esses conhecimentos e verificaremos o quanto eles intervêm no conhecimento pedagógico e curricular do conteúdo.

Nessa categoria, foi possível observar indícios de que não há muita clareza para os professores sobre a definição de números decimais. Alguns professores questionaram a definição ${ }^{3}$ e manifestaram dúvidas, como mostra as falas os sujeitos:

Solange: Porque ele fala assim também, as dízimas periódicas e os números irracionais não pertencem a esse conjunto. Mas se eu dividir três transformar em decimal e dividir, será que dá um número com vírgula, o número 3,75, eu posso escrever em fração, três mil trez̧entos e setenta e cinco dividido por cem, se eu dividir de novo, ai fica nessa...e...

João: Acaba ficando um número inteiro.

Alexandre: Isso me leva a outra pergunta: se é um denominador de potência de base dez, então, o inteiro quatro... Ele é um número decimal, porque a potência dez elevado a zero dá um. Então, um número inteiro é decimal também. Porque se todo número inteiro for decimal, eu respondi tudo errado.

João: Eu também.

[risos]

Essa questão causou certa polêmica no grupo; com isso, identificamos dúvidas na compreensão do que é um número decimal, e o fato de os números inteiros pertencerem ao conjunto dos decimais foi praticamente inaceitável pelo grupo, como podemos observar no diálogo a seguir:

Pesquisadora: [...] Ele diz que os números irracionais e as dízimas periódicas não pertencem a esse conjunto.

Veriani: É 0,75 é3 sobre 4, e as dí̃imas... 0,666... Não dá.

Pesquisadora: Eu não consigo escrever ela como uma potência de dez:

${ }^{3}$ Definição de números decimais apresentada na página 8. 
Veriani: Então não é decimal? Por quê? Então 0,333333333... Não é decimal?

Pesquisadora: Segundo essa definição, não.

Veriani: Mas eu não acredito nessa definição. [...] porque 0,333...é três décimo, três centésimo, três milésimo três. [...] Estranho né, é interessante, mas é estranho, né. Ficou um ponto de interrogação, tem que estudar, porque, pra mim, isso aqui sempre foi decimal, agora, tem parte inteira e parte decimal e não é decimal.

Segundo Esteves (2009), as lacunas existentes nas estruturas do conhecimento específico do conteúdo dos professores comprometem a compreensão acerca dos números decimais. Essas lacunas tornam o conhecimento específico do conteúdo dos professores muito próximo dos conhecimentos dos alunos.

Os resultados analisados por Padovan (2000) revelam que a representação escrita do número decimal é um dos fatores de influência na conceitualização dos números decimais. Para ela, a presença da vírgula é um indicativo muito forte para que um número seja considerado pelos alunos como decimal, pois, geralmente, são definidos por alunos e professores como números "com vírgula". A pesquisadora ainda afirma que, ao resumir a ideia do número à sua representação, perde-se a compreensão de seu real significado.

Segundo Shulman (1986), o conhecimento específico do conteúdo é fundamental na base de conhecimento para o ensino, haja vista que exerce influência direta nas seleções que os professores fazem sobre como e o que ensinar. Em conformidade com o autor, embora o conhecimento específico do conteúdo seja o conhecimento necessário para o ensino, ele não é suficiente para que esse ensino, de fato, torne-se compreensivo para os alunos. Entendemos que, como defendido por Shulman e seus colaboradores (1986, 1987, 1989), os conhecimentos específicos do conteúdo, neste caso os números decimais, recaem sobre os conhecimentos pedagógico e curricular desses professores.

Outro aspecto importante a ser ressaltado ao se fazer referência às operações envolvendo números decimais são as falsas generalizações de propriedades dos números naturais para os números decimais, principalmente quando realizamos operações de multiplicação e divisão. A forma mecanizada que, em geral, é trabalhada nas escolas não oferece aos alunos a oportunidade de compreender o que fazem (ZUNINO, 1995). Para Brousseau (1980, p. 27),

[...] o uso de um algoritmo está, em relação à atividade mental, como a parte visível de um iceberg. [...] De uma certa maneira, aprender separadamente os algoritmos de cálculo e as condições de emprego deles é uma atividade comparável àquela que consiste em aprender as citações e o lugar onde as colocar. Ela é concebível em literatura acadêmica, mas não permite aprender uma língua. 
Nesse sentido, observamos que o conhecimento dos professores investigados em relação às operações com decimais refere-se unicamente às técnicas algorítmicas, ou seja, sabem fazer, mas não conseguem explicar por que acontece dessa maneira. Acreditamos que a compreensão das operações com números decimais está diretamente relacionada à maneira como o professor ensina os seus alunos, o que se evidencia no diálogo a seguir:

Veriani: Na multiplicação de decimal, tem número que dá inteiro, tem número que não dá, e daí? Por que tem multiplicação que dá menor, multiplicação não é... Até isso eu não conseguia explicar para os meus alunos, na verdade, o que faz a multiplicaşão é aumentar, não é? Se eu multiplico, aumenta. Mas tem alguns decimais que multiplica não dá, ele diminui, e aí como é que você explica isso?

Pesquisadora: Sempre tem aquele aluno que pergunta, mas professora sempre aumentou, por que diminuiu?

Veriani: Até as dívidas dos meus alunos, eu nunca soube explicar por que o valor abaixa. Por que abaixa, você sabe me explicar?

Outro ponto de destaque em relação ao conhecimento da operação se deu durante o primeiro encontro ao se realizar uma atividade proposta que questionava a divisão de um décimo dividido por um centésimo ser igual a dez.

Veriani: Porque se fosse dez dividido por um você pega dez, dez dividido por um dá dez ai é uma coisa lógica.

Solange: [...] para que eu possa fazer a divisão, primeiramente, eu pensei, [...] isso aqui não é a mesma coisa que um sobre dez, mas qual que é a potência desse dezz é um sobre dez. elevado a um, [...] o outro não é um centésimo, escrevendo em potência de dezé é um sobre dez elevado ao quadrado, certo? Ai, eu transformei isso ai em fração equivalente, [...] dai, en multipliquei por dez, a fi ficon um sobre dez ou um sobre dez, elevado ao quadrado. Ok? João: Eu não coloquei na base dez, en fiz normalmente como en trabalbo, igualando as casas, igualando as casas e fazendo a divisão normal. Transformo em um número natural e faz a divisão.

Os resultados coadunam com os estudos de Ribeiro (2009). Para ele, "as operações com números fracionários, em particular decimais, por não serem tão intuitivas como as que envolvem números naturais (inteiros), são, por vezes, encaradas pelos professores como apenas um conjunto de regras [...]" (RIBEIRO, 2009 , p. 12). Encontramos essa afirmação na fala de Veriani ao explicar como, usualmente, ensina operações com decimais: "Mas aí o que a gente explica quando vai dividir, qual é a primeira coisa que a gente vai faz̧er na divisão de decimais, iguala as casas, segunda coisa, corta a vírgula, terceira coisa, zero à esquerda não tem valor".

Nesse sentido, Pérez (1997) observa, em primeiro lugar, que o quociente dos números decimais não é sempre um número decimal, portanto, o conjunto 
dos números decimais não é fechado para a divisão. Por exemplo, $1 / 2: 3 / 4=2 / 3$, $1 / 2$ e $3 / 4$ são números decimais, porém $2 / 3$ não é um número decimal, visto que não existe nenhum número decimal que multiplicado $3 / 4$ resulte em $1 / 2$.

$\mathrm{Na}$ escrita decimal, o número 0,5 : 0,75 não é um número decimal. Em segundo lugar, vemos que o modelo de divisão válido para os números naturais tampouco se pode estender para os números decimais.

Os PCN (1998) chamam a atenção para as possíveis dificuldades que possam surgir quando operamos com os racionais, na forma decimal, sendo uma explicação a essas dificuldades o fato de que a aprendizagem desse conjunto supõe rupturas com ideias construídas para o conjunto dos naturais. Por exemplo, "ao multiplicar um número natural por outro natural (sendo este diferente de 0 ou 1) a expectativa é a de encontrar um número maior que ambos, ao multiplicar 10 por $1 / 2$ se surpreenderão ao ver que o resultado é menor do que 10 ". (PCN, 1998, p. 101).

Nos fragmentos anteriores, identificamos dificuldades nas operações com números decimais. Percebemos também que a falha do conhecimento específico influencia nos conhecimentos pedagógico e curricular em relação às operações com decimais. Para Shulman (1986, 1987), o conjunto de conhecimentos indispensáveis ao professor compreende o conhecimento de princípios e técnicas de ensino e aprendizagem, englobando o conhecimento sobre os alunos e as formas de tornar o conteúdo compreensível aos alunos (WILSON; SHULMAN; RICHERT, 1987).

Em nossa pesquisa, observamos que o ensino das representações fracionária e decimal dos números racionais é realizado pelos professores, separadamente, dando-se mais ênfase ao trabalho com a representação fracionária do número racional.

Uma ponderação feita pela professora Veriani, relacionada a essa categoria que acreditamos evidenciar os aspectos do conhecimento específico e pedagógico do conteúdo de decimais, é a dificuldade apresentada pela professora para explicar que um mesmo número pode ter diferentes representações. Segundo ela,

[...] qual seria a verdadeira função trabalhar frações com decimais para eles entenderem isso, mas isso é muito dificil de ser trabalhado, primeiro por que o professor não consegue mostra isso o tempo todo, ele trabalha fração e depois trabalha decimal, ele não faz essa associação.

Nesse sentido, Alexandre relata que

[...] uma das minhas grandes dúvidas assim é como começar um trabalho no sexto ano, então, a gente poderia, às vežes, iniciar por isso aí, como que eu posso estar introduzindo, como que eu posso estar trabalhando decimal com uma turma de sexto ano é... [...] Porque, 
assim, não é o primeiro contato que eles vão ter com números decimais, porque se eu não me engano tem o pré até o quinto ano [...] Como que eu vou começar isso aqui sabendo que ele já deve ter visto?

No planejamento realizado pelo grupo, foi elaborada uma sequência de atividades, em que eles optaram que se partisse da representação fracionária para a representação decimal. Neste particular, concordamos com Bittar e Freitas (2005, p. 176) quando definem que "os números decimais são, portanto, muito mais 'naturais' para os alunos do que as frações, apesar de serem, usualmente, trabalhados nas escolas após o estudo de fração".

Os PCNs (1998, p. 103) corroboram quando orientam que, "Ao abordar os racionais pelo seu reconhecimento no contexto diário, deve-se observar que eles aparecem muito mais na forma decimal do que na forma fracionária".

Nas falas anteriores percebemos que, embora os professores não demonstrem um bom domínio conceitual do conteúdo em questão, há a identificação do conhecimento curricular do conteúdo, pois eles apresentam entendimento sobre a ordem de apresentação dos tópicos deste conteúdo.

Nessas falas transcritas, reconhecemos os três aspectos mencionados por Shulman (1986), para quem o conhecimento específico do conteúdo envolve a relação de diferentes tópicos dentro da mesma disciplina, assim como o conhecimento curricular vertical. Notamos que as diferentes formas de representar um mesmo conteúdo por meio dos materiais mostram o conhecimento pedagógico e curricular sobre números decimais.

Entretanto, observamos falhas desses conhecimentos em relação às representações do número racional. Durante a elaboração do planejamento, muitas dúvidas surgiram sobre como fazer os alunos visualizarem as duas representações por meio do material.

Alexandre - Esses questionamentos aí são para saber o que fazer na hora, por que a gente colocar passo a passo aqui, e quando chegar na hora, e aí? E essa parte aqui como é que en vou fazer?

Veriani - Eu entendi a preocupação do Alexandre, por quê? Porque os alunos têm a mesma dificuldade da gente de enxergar [...].

Junior - $O$ aluno vai ter [...].

Essas inquietações apresentadas pelos professores revelam falta de conhecimento pedagógico do conteúdo, o qual, segundo Alves e Gomes (2008, p. 1), está relacionado à dimensão do conhecimento de conteúdos para o ensino, "englobando a compreensão das diferentes formas de apresentar determinado conteúdo". 
Atentando-se à proposta de Shulman $(1986,1987)$, o conhecimento das concepções prévias dos alunos é fundamental para que o professor possa ter subsídios a fim de elaborar atividades que visem a reconstruir as concepções errôneas desses mesmos alunos. O pesquisador avalia que é necessário partir dos conhecimentos que os alunos já possuem para que o conteúdo não seja trabalhado de uma forma muito diferente de sua compreensão, de modo a promover a aprendizagem mais significativa e prazerosa.

A maneira como os professores trataram as dificuldades que eles e os alunos tiveram, durante o desenvolvimento do planejamento em sala, acerca das representações fracionária e decimal com o uso do material manipulável, assim como as opções feitas pelos professores acerca do que ensinar, a escolha das atividades para o planejamento e a maneira como desenvolveram o planejamento, tudo isso reflete as relações existentes entre os conhecimentos pedagógico, específico e curricular do conteúdo, conforme defendido por Shulman e seus colaboradores $(1986,1987,1989)$.

Em relação ao conhecimento do material manipulável elaborado para o ensino de números decimais, analisamos o modo como material elaborado pelo grupo ajudou ou influenciou na elaboração das atividades do planejamento, da mesma forma se colaborou na compreensão dos conceitos, nas relações entre as representações e nas operações envolvendo números decimais.

Nossa intenção ao propor o uso de um material manipulável para auxiliar as atividades vai ao encontro do relato da professora Solange, quando disse: "Mas assim, qual a vantagem de trabalhar com o material manipulável? O aluno manipula e consegue compreender, porque até então um décimo e dois décimos e qualquer coisa é a mesma coisa por que ele não entende nada [...]” (E4).

O uso de materiais manipuláveis é visto por muitos professores como facilitador na aprendizagem de conceitos matemáticos. Segundo Fiorentini (1995), os materiais podem ser considerados uma construção empírico-ativista ${ }^{4}$. Esta tendência vê o conhecimento matemático como algo que emerge do mundo físico e é extraído pelo homem através dos sentidos.

Shulman (1986) ao se referir aos materiais do currículo, o qual inclui também os materiais manipuláveis, questiona:

Quantos indivíduos dos quais nós preparamos para ensinar [...] entendem bem os materiais para essa instrução, os textos alternativos, softwares, programas, materiais visuais, filmes de conceitos simples, demonstrações laboratoriais, ou 'convites para pesquisa'? Nós confiaríamos em um médico que

\footnotetext{
${ }^{4}$ A concepção empírico-ativista surgiu, no Brasil, na década de 20, em meio ao movimento escolanovista, valorizando os processos de aprendizagem envolvendo o aluno em atividade e entende a manipulação ou a experimentação como condição necessária para a aprendizagem.
} 
não entendesse realmente das formas alternativas de lidar com categoriais de doenças contagiantes, e que só soubesse de uma forma? (SHULMAN, 1986, p. 13).

Shulman et al. (1989) assinala que o estilo de instrução do professor, as críticas que ele faz aos materiais manipuláveis, a maneira como seleciona um material a ser ensinado, enfim, a forma como organiza e desenvolve o processo de ensino de um determinado conteúdo apontam o conhecimento sobre o conteúdo específico que possui. Assim, os conhecimentos que os professores apresentaram sobre o conteúdo de números decimais, ou a falta deles, interferiram também na escolha do material.

Podemos notar, nas falas anteriores, neste tópico, indícios da necessidade do conhecimento específico do conteúdo para a construção do conhecimento pedagógico e curricular do conteúdo, conforme defendido por Wilson; Shulman e Richert (1987). Reiteramos que o conhecimento pedagógico e curricular do conteúdo é fundamental para que o professor consiga elaborar de maneira adequada as situações didáticas a serem trabalhadas com o uso de materiais manipuláveis para, assim, poder explorar os conceitos que pretende ensinar (IBID, 1987).

\section{Considerações finais}

Os conhecimentos investigados neste trabalho foram os definidos como Base de Conhecimentos para o Ensino por Shulman (1986), a saber: conhecimento específico do conteúdo, pedagógico do conteúdo e curricular. De acordo com Shulman (1986), esses conhecimentos não podem ser analisados separadamente, por isso buscamos identificar o entrelaçamento deles por meio de seis encontros realizados com os professores, sujeitos deste trabalho. Embora pareça relativamente simples falar sobre os conhecimentos que os professores possuem sobre números decimais, percebemos a complexidade do trabalho docente ao analisar as conexões entre os conhecimentos elencados por Shulman.

A partir dos dados coletados, foi possível detectar que as dificuldades dos conhecimentos específicos do conteúdo em questão levaram os sujeitos da pesquisa a ter dificuldades na escolha e na elaboração de um material didático dentro do processo de ensino e aprendizagem do conteúdo de números decimais. Mais especificamente, em relação ao conhecimento específico do conteúdo, esses professores apresentaram lacunas em suas estruturas substantivas e sintáticas e, principalmente, nas operações de multiplicação e divisão.

Com isso, certificamo-nos do pouco domínio no que se refere ao conhecimento pedagógico do conteúdo: a) na utilização de técnicas algorítmicas para 
realizar as operações; b) na opção, por parte do grupo, em elaborar o planejamento partindo das frações para chegar aos números decimais; c) na prioridade ao trabalho com as frações do que com os números decimais; e d) na maneira que trataram as dificuldades apresentadas pelos alunos durante o desenvolvimento das atividades do planejamento.

A falta de familiarização de tópicos trabalhados com os que ainda serão ensinados, envolvendo os materiais que fazem parte deles, demonstra a falta de domínio do conhecimento curricular do conteúdo, como aponta Shulman (1986). Percebemos, por meio dos dados, a necessidade de garantir ao professor a constituição sobre a base de conhecimento para o ensino de um conteúdo, como denotam as pesquisas realizadas por Shulman $(1986,1987)$.

Sabemos, conforme já apontado em várias pesquisas, que é dada pouca atenção aos conhecimentos matemáticos necessários para a atuação do professor na Educação Básica nos cursos de licenciatura. A pesquisa desenvolvida por Oliveira (2010) evidenciou, na prática de um sujeito, a estreita relação existente entre os conhecimentos da formação inicial e os mobilizados na sua prática pedagógica, apontando o papel fundamental da licenciatura para o preparo do futuro professor. O estudo revelou também a importância dos diversos tipos de conhecimentos que devem estar presentes de forma consistente na formação inicial.

As análises mostraram a necessidade de readequação dos cursos de formação continuada. Os cursos de formação continuada no Brasil estão, geralmente, vinculados à ideia de frequentar cursos em que os assuntos são tratados de forma compartimentada, buscando atingir aquilo que se acredita ser uma carência do professor. Com isso, as angústias, os interesses e as necessidades não são o foco, evidenciando a baixa eficácia e abrangência dos referidos cursos, não atingindo mudança na prática do professor (GAMA, 2007).

Ponte (1999, p. 17) postula que "é preciso que o trabalho de formação não destrua o gosto pela disciplina, antes o desenvolva e o ajude a amadurecer". O autor argumenta ainda que é importante que as instituições de ensino superior não apenas transmitam conhecimentos, mas ensinem, também, a produzir novo conhecimento.

Os dados, ademais, levaram-nos a refletir sobre a necessidade de ambientes que possibilitem discussões entre professores, principalmente na elaboração de planejamentos. O presente estudo aponta ainda o quanto os materiais didáticos manipuláveis caracterizaram-se favoráveis ao ensino e à aprendizagem dos números decimais. Outro ponto que merece novamente ser destacado foi que o trabalho realizado em grupo teve grande importância por considerar a 
reflexão sobre a prática, o conhecimento e o desenvolvimento profissional de cada sujeito.

As análises revelaram, além disso, que os encontros entre professores e pesquisadores contribuíram para que os sujeitos expusessem suas dúvidas, suas experiências e seus conhecimentos, refletindo sobre a sua prática e percebessem a necessidade dos conhecimentos específicos do conteúdo, pedagógicos do conteúdo e curricular.

Enfim, a investigação realizada defrontou-se com a fragilidade dos conhecimentos dos professores observados em relação aos números decimais. Evidenciou a relação existente entre os conhecimentos que compõem a base de conhecimento para ensino proposta por Shulman (1986). Valorizou a importância das discussões em grupo e, principalmente, do planejamento elaborado em grupo, evidenciando o papel fundamental da formação continuada na prática do professor, bem como a maneira que os sujeitos participantes esperam que esses cursos aconteçam. Mais do que isso, mostrou a importância dos conhecimentos que devem estar presentes e poderão ser construídos na formação continuada, quando, principalmente, se valoriza a participação dos professores.

\section{Referências}

ALVES, B.; GOMES, A. Operações com números decimais: o conhecimento de professores do 1. ${ }^{\circ}$ C. E. B. In: PROFMAT, 24., 2008, Elvas. Actas... Elvas: Associação de Professores de Matemática, 2008. p. 1-13.

ARAÚJO, J. de L.; BORBA, M. de C. Pesquisa qualitativa em Educação Matemática. Belo Horizonte: Autêntica, 2004. (Tendências em Educação Matemática).

BARDIN, L. Análise de conteúdo. 4. ed. Lisboa, 2008.

BITTAR, M.; FREITAS, J. L. M. de. Fundamentos e metodologia de matemática para os Ciclos Iniciais do Ensino Fundamental. 2. ed. Campo Grande: UFMS, 2005.

BOGDAN, R.; BIKLEN, S. K. Investigação qualitativa em educação: uma introdução à teoria e aos métodos. Portugal: Porto Editora, 1994.

BOYER, C. B. História da matemática. Tradução de Elza F. Gomide. 2. ed. São Paulo: Edgard Blüncher, 1996.

BOLZAN, D. Formação de professores: compartilhando e reconstruindo conhecimento. Porto Alegre: Mediação, 2002.

BORGES, C.; TARDIF, M. Saberes docentes: diferentes tipologias e classificações de um campo de pesquisa. Educação \& Sociedade, Campinas, v. 22, n. 74, p. 59-76, abr. 2001. DOI: $10.1590 /$ S0101-73302001000100005

BRASIL. Secretaria de Educação Fundamental. Parâmetros Curriculares Nacionais: Matemática. Brasília: MEC/SEF, 1998. 
CURI, E. Formação de professores polivalentes: uma análise de conhecimentos para ensinar matemática e de crenças e atitudes que interferem na constituição desses conhecimentos. 2004. 278 f. Tese (Doutorado em Educação Matemática) - Pontifícia Universidade Católica de São Paulo, São Paulo, 2004.

ESTEVES, A. K. Números decimais na Escola Fundamental: interações entre os conhecimentos de um grupo de professores e a relação com sua prática pedagógica. 2009. 153 f. Dissertação (Mestrado em Educação Matemática) - Universidade Federal do Mato Grosso do Sul, Campo Grande, 2009.

FIORENTINI, D. Pesquisar práticas colaborativas ou pesquisar colaborativamente? In: BORBA, M. de C.; ARAUJO, J. de L. (Orgs.). Pesquisa qualitativa em Educação Matemática. Belo Horizonte: Autentica, 2004. p. 47-76. (Coleção - Tendências em Educação Matemática).

FRANCO, M. L. P. B. Análise do conteúdo. 3. ed. Brasília: Líber Livros, 2008. (Série Pesquisa, v. 6).

GAMA, R. P. Desenvolvimento profissional com apoio de grupos colaborativos: o caso de professores de matemática em inicio de carreira. 2007. 240 f. Tese (Doutorado em Educação) - Universidade Estadual de Campinas, Campinas, 2007.

IFRAH, G. História universal dos algarismos. Rio de Janeiro: Nova Fronteira, 1997. v. 1; 2.

MIZUKAMI, M. G. N. et al. Escola e aprendizagem da docência: processos de investigação e formação. São Carlos: EDUFSCar, 2002.

- Aprendizagem da docência: algumas contribuições de L. Shulman. Revista do Centro de Educação, Santa Maria, v. 29, n. 2, p. 33-49, jul./dez. 2004.

MOREIRA, P. C.; DAVID, M. M. M. S. A formação matemática do professor: licenciatura e prática docente escolar. Belo Horizonte. Autêntica, 2007.

NACARATO, A. M. O conceito de números. Revista das Faculdades de Educação, Ciências e Letras e Psicologia Padre Anchieta, Jundiaí, v. II, n. 3, p. 84-106, jan. 2000.

NIVEN, I. M. Números: racionais e irracionais. Tradução de Renate Watanabe. Rio de Janeiro: Sociedade Brasileira de Matemática, 1984.

OLIVEIRA, A. B. de. Prática pedagógica e conhecimentos específicos: um estudo com um professor de matemática em início de docência. 2010. 169 f. Dissertação (Mestrado em Educação Matemática) - Universidade Federal de Mato Grosso do Sul, Campo Grande, 2010.

PADOVAN, D. Números decimais: o erro como caminho. 2000. 145 f. Dissertação (Mestrado em Educação) - Universidade de São Paulo, São Paulo, 2000.

PÉREZ, J. C. Numeros decimales por qué? para qué? São Paulo: Editorial Síntesis, 1997.

PENTEADO, C. B. Concepções do professor do ensino médio relativas a densidade do conjunto dos números reais e suas relações frente a procedimentos para a abordagem desta propriedade. 2004. 247 f. Dissertação (Mestrado em Educação Matemática) Pontifícia Universidade Católica de São Paulo, São Paulo, 2004.

PIATTI, C. B. Formação continuada: questões que suscitam. Revista Profissão Docente, Uberaba, v. 6, n. 14, p. 89-98, out./dez. 2006. 
PONTE, J. P. Perspectivas de desenvolvimento profissional de professores de Matemática. In: PONTE, J. P.; MONTEIRO, C.; MAIA, M.; SERRAZINA L.; LOUREIRO, C. (Eds.). Desenvolvimento profissional dos professores de matemática: que formação? Lisboa: SPCE, 1996. p. 193-211.

A investigação sobre o professor de matemática problemas e perspectivas. Serra Negra - SP, nov. 2000. (Conferência realizada no I Seminário Internacional de Pesquisa em Educação Matemática - SIPEM, promovido pela Sociedade Brasileira de Educação Matemática - SBEM).

. Didácticas específicas e construção do conhecimento profissional. In: CONGRESSO DA SOCIEDADE PORTUGUESA DE CIÊNCIAS DA EDUCAÇÃO, 4., 1999, Porto. Actas... Porto: SPCE, 1999. p. 59-72.

RIBEIRO, C. M. Abordagem aos números decimais e suas operações: a importância de uma "eficaz navegação" entre representações. Centro de Investigação sobre o Espaço e as Organizações (CIEO), Universidade do Algarve, 2009.

SCHWAB, J. Structure of the disciplines. In: FORD, G. W.; PUGNO, L. (Eds.). The structure of knowledge and the curriculum. Skokie: Rand McNally, 1964.

SILVA, R. G. Interações entre licenciandos em matemática e pedagogia: um olhar sobre o ensino do tema grandezas e medidas. 2010. 184 f. Dissertação (Mestrado em Educação Matemática) - Universidade Federal do Mato Grosso do Sul, Campo Grande, 2010.

SHULMAN, L. Those who understand: knowledge growth in teaching. Educational Researcher, v. 15, n. 2, p. 4-14, feb. 1986. DOI: 10.3102/0013189X015002004 Knowledge and teaching: foundations of the new reform. Harvard Educational Review, v. 57, n. 1, p. 1-22, feb. 1987.

SHULMAN, L.; WILSON, S. M.; GROSSMAN, P. L. Teachers of Substance: subject matter knowledge for teaching. In: Knowledge Base for the Beginning Teacher. MAYNARD, C.; REYNOLDS. (Ed.). For the American Association of Colleges for Teacher Education. Nova Yorque: Pergamon Press, 1989. p. 23-36.

SHULMAN, L.; WILSON, S. M.; RICHERT, A. E. 150 different way's of knowing: representations of knowledge in teaching. Exploring Teachers Thinking, 1987.

ZUNINO, D. L. A matemática na escola: aqui e agora. Porto Alegre: Artes Médicas, 1995.

Recebido em 19/03/2012

Aceito em 10/09/2012 